\title{
Chronic Pain after Cesarean Section. Influence of Anesthetic/Surgical Technique and Postoperative Analgesia
}

\author{
Thais Orrico de Brito Cançado 1, Maruan Omais ${ }^{1}$, Hazem Adel Ashmawi 2, Marcelo Luis Abramides Torres ${ }^{3}$
}

Summary: Cançado TO, Omais M, Ashmawi HA, Torres MLA - Chronic Pain after Cesarean Section. Influence of Anesthetic/Surgical Technique and Postoperative Analgesia.

Background and objectives: Brazil ranks second among countries with the highest rates of cesarean section in the world. Little is known about the future consequences of this procedure on maternal health. This study investigated the influence of anesthetic/surgical technique and postoperative analgesia on the onset of chronic pain after three months of cesarean section.

Method: This is a prospective randomized study of 443 patients undergoing cesarean section (elective and emergency), with different doses of hyperbaric bupivacaine $0.5 \%$ and opioids in spinal anesthesia. Patients were alocated into five groups as follow: G1 received hyperbaric bupivacaine $(8 \mathrm{mg})$, sufentanil $(2.5 \mu \mathrm{g})$, and morphine $(100 \mu \mathrm{g})$; G2 received hyperbaric bupivacaine $(10 \mathrm{mg})$, sufentanil $(2.5 \mu \mathrm{g})$, and morphine $(100 \mu \mathrm{g})$; G3 received hyperbaric bupivacaine $(12.5 \mathrm{mg})$ and morphine $(100 \mu \mathrm{g})$; G4 received hyperbaric bupivacaine (15 mg) and morphine $(100 \mu \mathrm{g})$; G5 received hyperbaric bupivacaine $(12.5 \mathrm{mg})$ and morphine $(100 \mu \mathrm{g})$, without perioperative anti-inflammatory. Pain at rest and in movement were evaluated in the immediate postoperative period. Phone contact was made after three months of surgery for identification of patients with chronic pain.

Results: The incidence of chronic pain in the groups was G1 $=20 \%$; G2 $=13 \%$; G3 $=7.1 \%$; G4 $=2.2 \%$, and G5 $=20.3 \%$. Patients who reported higher pain scores in the postoperative period had a higher incidence of chronic pain $(p<0.05)$.

Conclusion: The incidence of chronic pain decreases with higher doses of local anesthetics and use of anti-inflammatory drugs. The higher pain scores in the postoperative period were associated with chronic pain development after three months of cesarean section.

Keywords: Anesthesia, Spinal; Cesarean Section; Chronic Pain; Pain, Postoperative.

@2012 Elsevier Editora Ltda. All rights reserved.

\section{INTRODUCTION}

There is increasing evidence that perioperative anesthetic/ surgical management has consequences that extend far beyond the immediate recovery period, such as postoperative chronic pain (POCP).

Currently, there is a tendency in the literature to use the term persistent postoperative pain (PPOP), but the persistent postoperative pain definition remains controversial because it is difficult to determine if the pain is just a continuation of the preoperative condition or if it arises after surgical procedure. It has been suggested that the criterion for persistent postoperative pain diagnosis should include postoperative pain that lasts for at least two months after surgery, with the exclusion

Received from Hospital das Clínicas da Universidade de São Paulo (USP), Brazil.

1. MD; Postgraduation sutdent, Faculdade de Medicina, Universidade de São Paulo, (USP), Brazil.

2. PhD in Medicine, Faculdade de Medicina, USP.

3. PhD Professor, Faculdade de Medicina, USP.

Submitted on October 20, 2011.

Approved on December 21, 2011.

Correspondence to:

Thais Orrico de Brito Cancado, MD

Hospital das Clínicas da Universidade de São Paulo

Av. Dr. Arnaldo 455

01246-903 - São Paulo, SP, Brazil

E-mail: thaiscancado@terra.com.br of other causes for pain occurrence. The preoperative conditions that had its preexisting painful condition exacerbated because of the surgery should also be excluded as potential causes of persistent pain ${ }^{1}$.

Although open to criticism, a simplistic definition was suggested in 1999 by the International Association for the Study of Pain (IASP), in which chronic pain has been considered as pain persisting for more than three months after surgery (in a continuously or intermittently manner), excluding other causes for its occurrence ${ }^{2}$.

POCP is present in up to $80 \%$ of surgical procedures, including amputations, thoracotomy, herniorrhaphy, cholecystectomy, and mastectomy ${ }^{3}$. The wide variation in incidence may be due to the various definitions of POCP used in several studies.

Cesarean section rates are increasing worldwide every year, and there is concern about the consequences of different methods of delivery on maternal health. Because this procedure rate is increasing, the study of its effects on the future life of women is necessary.

The 2008 data of the Ministry of Health Information System on Live Births (Sisnasc) show that from 2.9 million deliveries annually made in Brazil, $43 \%$ were cesarean sections ${ }^{4}$. In private metropolitan health networks, these indicators reach $90 \%$, placing Brazil in second among the highest rates of cesarean surgeries in the world. These figures show the magnitude of this event; however, little is known about chronic pain after obstetric surgery. 
Management of postoperative pain after a cesarean section is rather different from other surgeries, mainly because the woman needs a fast recovery to take care of the newborn. One should choose drugs and techniques that do not alter the consciousness and ability to walk. Moreover, drugs used for treatment or prevention of postoperative pain may affect the fetus and newborn through placental circulation or breastfeeding 5 .

There is consensus in the literature that drug combination (combined or multimodal analgesia) is mandatory for achieving satisfactory and effective pain relief and side effects prevention, as the combined use of drugs achieves the desired effect of analgesia with lower doses $6,7,8$.

Given the above information, the role of the anesthesiologist in controlling postoperative analgesia is highlighted - a role that begins at the moment of choosing the type of anesthesia to be used in pregnant women and may be extended up to the time of hospital discharge ${ }^{9}$.

Considering that cesarean section is actually one of the most performed procedures, which may cause chronic pelvic pain, sometimes debilitating and undermining the quality of life of women, a prospective study on the subject is warranted.

The aim of this study was to evaluate prospectively the effect of different doses of local anesthetics and opioids in spinal anesthesia, as well as the use of anti-inflammatory in persisted pain three months after cesarean section.

\section{METHOD}

After approval by the Ethics Research Committee (CAPPesq) of the Hospital das Clinicas, Faculdade de Medicina da Universidade de São Paulo (HC-FMUSP), and Ethics Research Committee of the Association for Motherhood and Childhood Support (AAMI), this prospective study was performed with the follow-up of 443 pregnant patients who underwent cesarean section under spinal anesthesia from January to December 2009.

Inclusion criteria were patients who had no clinical contraindications to spinal blockade, age above 18 years, height between 150 and $175 \mathrm{~cm}$, and those who reported no allergy to drugs used in the protocol. Women with a history of chronic pain and abuse of illicit drugs were excluded from the study.

Patients with indication for cesarean section and who met the above criteria were alocated into five random groups, distributed according to the dose of local anesthetics and opioids used in the subarachnoid space and the use of anti-inflammatory drugs (NSAIDs) in the intra- and post-surgery periods. Groups were determined according to the random sequence of numbers obtained through the site www.random.org ${ }^{10}$. A sequence was generated with the numbers 1 to 5 , corresponding to the groups (500 numbers in total), and patients were assigned to groups according to this sequence.

A detailed history was taken before the patient was transported to the operating room. We collected information on patient's characteristics (age, race, marital status, family income, weight, and height), surgical and pathological history, and obstetric history (gestational age, parity).

Upon arrival to the operating room, routine monitoring was performed (NIBP, ECG, $\mathrm{SpO}_{2}$ ), venipuncture with catheter 20G, hydration with Ringer's lactate $\left(10 \mathrm{~mL} . \mathrm{kg}^{-1}\right)$ until birth and spinal puncture between L1-L5 in the sitting position using a 27G Quincke needle. Drugs were administered using the same syringe, according to group's distribution determined by randomization (Table I). There was manual womb deviation until birth, and hypotension, if present, was corrected with ephedrine hydrochloride.

Any intraoperative complications were noted, such as hypotension, pain, bradycardia, shivering, nausea, vomiting, and drowsiness. For treating vomiting, intravenous ondansetron (4 mg) was used; and for anesthesia complementation, 50 to $100 \mu \mathrm{g}$ fentanyl sulfate was used when necessary. After placenta removal, a continuous infusion of Ringer's lactate containing oxytocin 10Ul, dipyrone $2 \mathrm{~g}$, metoclopramide $20 \mathrm{mg}$, cephalothin $2 \mathrm{~g}$, and tenoxicam $40 \mathrm{mg}$ was maintained, except for patients in group 5 who did not receive anti-inflammatory medication at any time.

Surgery was performed via Pfannenstiel incision and uterine approach in the transverse direction. The use of forceps for fetal extraction, exteriorization of the uterus, and peritonization technique (visceral and/or parietal or no peritonization) for cavity closure was recorded. At the end of surgery, patients were taken to the post-anesthesia care unit (PACU).

Table I - Classification of Groups according to Local Anesthetics and Opioids Used in Spinal Anesthesia and NSAIDs Used in Late Postoperative Period

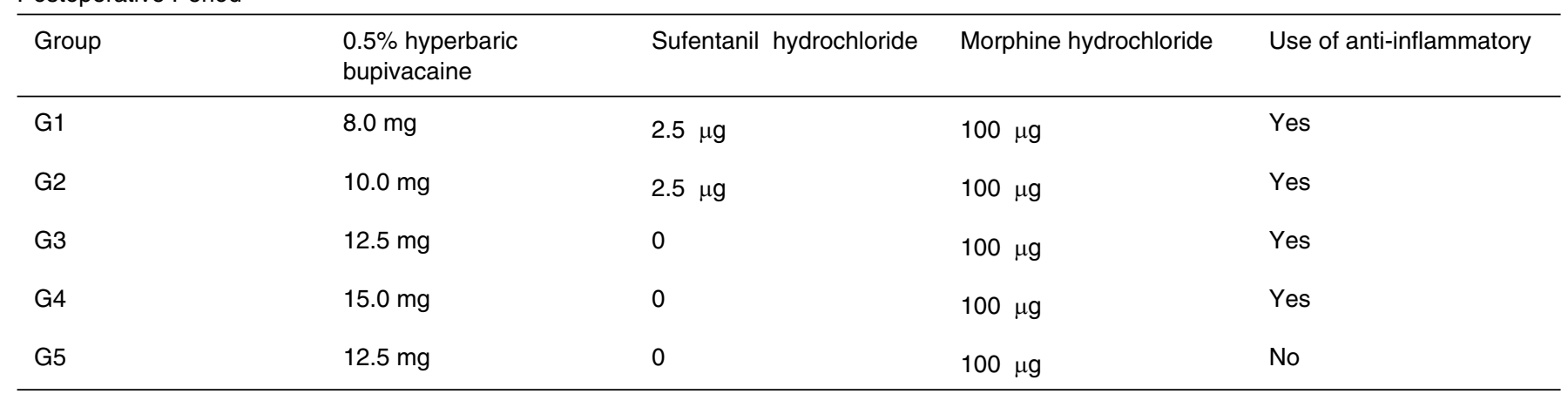




\section{Early postoperative period (first and second day after cesarean)}

In the immediate postoperative period, patients were medicated with intravenous dipyrone $1 \mathrm{~g}$ every 6 hours. After venous access removal, patients received oral dipyrone $500 \mathrm{mg}$ every 6 hours and diclofenac $50 \mathrm{mg}$ every 8 hours (except group 5).

Patients were interviewed on two occasions in the postoperative period (interview 1 after getting up and showering, about 12 hours after surgery; and interview 2 on the morning of the second postoperative day). Postoperative analgesia was assessed using a verbal numerical pain scale (VNS $0=$ no pain and VNS $10=$ the worst pain imaginable). The pain score reported by the patient before getting out of bed on the first postoperative day was considered pain score at rest. The pain score after getting up and walking was considered pain on movement in the first postoperative day (interview 1). On the second postoperative day (interview 2), we recorded pain scores at rest and on movement. Thus, four scores of postoperative pain were obtained.

\section{Late postoperative period}

Patients were contacted by phone in the third month after surgery by a nurse who was unaware of which group the patients belonged to. Patients were asked about the presence of any discomfort. Patients considered to have chronic pain were those who spontaneously reported the presence of abdominal or pelvic pain, tingling, pricking or sharp pain in the region near the incision after three months of surgery. Complains of numbness or decreased sensation in the region close to the scar was not considered chronic pain.

All data were statistically assessed, with results considered statistically significant at a $p$-value $<0.05$. Chi-square, likelihood ratio, Fisher's exact, Student $t$, and Mann-Whitney tests were used. Variables with statistical significance in univariate tests $(p<0.05)$ were included in a multiple logistic regression analysis to identify which combined variables could be related to chronic pain ${ }^{11}$.

\section{RESULTS}

After one year of data collection, a partial statistical analysis was performed to compare postoperative analgesia between groups and it was decided to stop the study due to the significant difference observed in group $5(p<0.001)$. There was also a significant difference between group 1 and group $4(\mathrm{p}<0.05)$ (Table II). Patients in groups 1 and 5 reported higher pain scores in the immediate postoperative period. Therefore, the total number of patients was 443 . Due to loss of telephone contact on the third postoperative month, 41 patients were excluded (9.25\%), so 402 patients underwent final statistical analysis. The groups were not uniform in number of patients, but they were comparable in age, height, weight, and gestational age (Table III).

Table IV shows the information about the anesthetic/surgical procedures (anesthetic group, type of surgery, and peritonization) related to the presence or absence of chronic postoperative pain.

Table IV shows a significant difference in the incidence of chronic pain between groups $(p=0.001)$. It can be observed a higher incidence of chronic pain in groups 1 and 5 . The variable nature of the surgery and peritonization showed no statistically significant differences regarding the presence of chronic pain.

Table $\mathrm{V}$ shows the correlation between the mean values and standard deviation of pain scores at rest and on movement of groups in interviews 1 and 2 regarding the occurrence of chronic pain. The values of pain scores at rest and on movement in interviews 1 and 2 were significantly higher in patients with chronic pain $(p<0.001$ and $p<0.014)$.

Table II - Results of Multiple Comparisons of Mean Score of Postoperative Pain (Interviews 1 and 2) between Groups

\begin{tabular}{llllll}
\hline Comparison & Mean difference & Standard Deviation & $\mathrm{p}$ & \multicolumn{1}{c}{$\mathrm{Cl}(95 \%)$} & Lower \\
\hline & & & & -0.11 & 1.54 \\
G1 - G2 & 0.715 & 0.3 & 0.123 & -0.22 & 1.35 \\
G1 - G3 & 0.565 & 0.285 & 0.275 & -2.13 & -0.44 \\
G1 - G5 & -1.286 & 0.308 & $<0.001$ & 0.15 & 1.73 \\
G1 - G4 & 0.942 & 0.289 & 0.011 & -0.89 & 0.59 \\
G2 - G3 & -0.15 & 0.271 & 0.981 & -2.81 & -1.19 \\
G2 - G5 & -2.001 & 0.296 & $<0.001$ & -0.53 & 0.98 \\
G2 - G4 & 0.227 & 0.276 & 0.923 & -2.62 & -1.09 \\
G3 - G5 & -1.851 & 0.28 & $<0.001$ & -0.33 & 1.09 \\
G3 - G4 & 0.377 & 0.258 & 0.59 & $<0.001$ & 3.01 \\
G5 - G4 & 2.228 & 0.284 & $<$ & \\
\hline
\end{tabular}


Table III - Demographic Data of Patients

\begin{tabular}{llllll}
\hline Group & $\begin{array}{l}\mathrm{G} 1 \\
(\mathrm{n}=65)\end{array}$ & $\begin{array}{l}\mathrm{G} 2 \\
(\mathrm{n}=77)\end{array}$ & $\begin{array}{l}\mathrm{G} 3 \\
(\mathrm{n}=99)\end{array}$ & $\begin{array}{l}\mathrm{G} 4 \\
(\mathrm{n}=92)\end{array}$ & $\begin{array}{l}\mathrm{G}=9 \\
(\mathrm{n}=69)\end{array}$ \\
\hline Age (years) & $26.6 \pm 6.0$ & $26.9 \pm 5.5$ & $27.0 \pm 6.2$ & $26.3 \pm 5.3$ & $25.0 \pm 5.5$ \\
Weight (kg) & $62.4 \pm 12.4$ & $58.9 \pm 12.5$ & $63.3 \pm 13.9$ & $63.7 \pm 14.1$ & $61.7 \pm 15.4$ \\
Height (cm) & $163 \pm 6.2$ & $160 \pm 5.7$ & $162 \pm 6.1$ & $164 \pm 6.3$ & $161 \pm 6.3$ \\
Gestational age (weeks) & $37.92 \pm 1.0$ & $38.06 \pm 1.6$ & $38.40 \pm 1.6$ & $38.77 \pm 1.0$ & $38.52 \pm 1.9$ \\
\hline
\end{tabular}

$p>0.05$ (ANOVA).

Table IV - Correlation between Anesthetic Group, Nature of Surgery, and Peritonization with Presence or Absence of Chronic Postoperative Pain



Table V - Correlation between Verbal Numerical Pain Score at Rest and in Movement (Mean Value and Standard Deviation) of Groups on Interviews 1 and 2 Regarding Chronic Pain Occurrence

\begin{tabular}{llll}
\hline \multicolumn{2}{l}{ Pain Score ( mean \pm standard deviation) } & No & p \\
\hline Chronic pain & Yes & & $<0.001$ \\
Interview 1 & & $1.70 \pm 2.20$ & $<0.001$ \\
Pain at rest & $3.20 \pm 2.90$ & $2.66 \pm 2.49$ & $<0.014$ \\
Pain on movement & $4.61 \pm 3.09$ & & $<0.001$ \\
Interview 2 & $2.35 \pm 2.43$ & $1.40 \pm 1.88$ & $1.99 \pm 2.31$ \\
Pain at rest & $3.61 \pm 2.80$ & & \\
Pain on movement & & \\
\hline
\end{tabular}


Table VI - Results of Logistic Regression Analysis of Variables Associated with Chronic Pain in Isolated Tests

\begin{tabular}{lllll}
\hline Variable & OR & $\begin{array}{c}\mathrm{Cl}(95 \%) \\
\text { Lower }\end{array}$ & Upper & \\
\hline Group & & & & \\
G4 & 1.00 & & & \\
G1 & 8.26 & 1.71 & 39.90 & 0.009 \\
G2 & 4.21 & 0.83 & 21.25 & 0.082 \\
G3 & 3.33 & 0.65 & 17.00 & 0.147 \\
G5 & 8.86 & 1.87 & 42.00 & 0.006 \\
\hline
\end{tabular}

A multiple logistic regression model was adjusted to all variables showing statistical significance for chronic pain, in isolated tests, to identify which combined variables were correlated with chronic pain (Table VI).

Table VI shows that patients in groups 1 and 5 were eight times more likely to develop chronic pain after cesarean section than patients in group 4. The other groups (2 and 3) showed the same statistical chance of developing chronic pain as the group with the highest dose of anesthesia (group 4) $(p>0.05)$.

\section{DISCUSSION}

An extensive literature search identified few studies with information regarding the incidence of chronic pain after cesarean section. The first article on chronic pain after cesarean section (the most common surgery and tending to increase) was published in 2004 by Nikolajsen et al. ${ }^{12}$ That retrospective study evaluated 220 women who underwent cesarean section, using a questionnaire. Patients gave information about the onset or persistence of pain after surgery. When pain was present, patients were asked about its intensity and interference with daily activities. The conclusion drawn was that postoperative pain disappeared in most patients after three months of surgery. After that time, an incidence of $18.6 \%$ was found and, after 10 months, the incidence dropped to $12.3 \%$. For $5.9 \%$ of patients treated, pain was a significant problem that interfered with quality of life. The higher incidence of chronic pain related to patients who received general anesthesia $(p<0.02)$, had pain at other sites $(p<0.0001)$, and those with severe pain in the postoperative period $(p<0.04)^{12}$.

In our study, the incidence of chronic pain was $11.44 \%$ after three months of surgery. Without taking into account the patients in group 5, who were not given NSAIDs, the incidence of chronic pain three months after surgery dropped to $7.96 \%$. There was a lower incidence of chronic pain compared with the Belgian study $(7.96 \%$ vs. $18.6 \%)$, perhaps because we considered patients who received only spinal anesthesia.
Nikolajsen et al. ${ }^{12}$ found higher incidence of chronic pain in patients who received general anesthesia and believe that the type of anesthesia is an important predictive factor for developing chronic postoperative pain ${ }^{12}$.

Luijendijk et al. ${ }^{13}$ evaluated 243 patients who underwent various types of abdominal surgery with Pfannenstiel incision and found that the incision length was a risk factor for increased incidence of pain ${ }^{13}$. In our study, all patients underwent a Pfannenstiel incision, but the incision size was not considered.

Rafique et al. ${ }^{14}$ studied the relationship between closure and non-closure of the visceral and parietal peritoneum and pain intensity after cesarean section. They concluded that postoperative pain intensity was greater with peritoneal closure. In our study, there was no significant relationship between the onset of chronic postoperative pain and peritoneal closure $(p=0.823)^{14}$.

A limitation of our study was the performance of cesarean sections by different surgical teams. Obviously, it would be very difficult for a single surgical team to develop this protocol; however, the differences in the techniques used by obstetricians are not significant in our institutions. In an attempt to minimize this limitation, the analysis included the type of peritonization used for closing the cavity; if there was uterine exteriorization, use of tampons in the cavity, and fetal extraction using forceps. There were no differences regarding the presence of chronic pain among these groups.

Eisenach et al. ${ }^{15}$ evaluated the type of delivery (vaginal or cesarean) and its correlation with depression or persistent pain, assessed eight weeks after surgery ${ }^{15}$. The authors found that the most important predictive factor for depression and persistent pain was acute postoperative pain.

Sng et al. ${ }^{16}$ published a study evaluating the incidence of chronic pain after cesarean section under spinal anesthesia in the Asian population. Spinal anesthesia was performed with hyperbaric bupivacaine $(10 \mathrm{mg})$ and morphine $(100 \mu \mathrm{g})$ and postoperative analgesia with patient controlled analgesia (PCA) pump containing morphine. Patients were followed for 24 hours and there was no reference regarding the use of anti-inflammatory drugs. The authors found a $9.2 \%$ incidence of chronic pain. The independent risk factors associated with chronic pain were higher levels of pain postoperatively, presence of pain in other sites, and lack of health insurance ${ }^{16}$. We found in our work on a similar group (group 2) a $13 \%$ incidence of chronic pain. It was used the same dose of local anesthetic and intrathecal morphine, but there was difference in the approach used in postoperative analgesia (PCA pump versus intermittent intravenous analgesia). The Chinese investigators considered only elective surgeries and there was no peritoneum closure in all cases, which may explain the lower incidence found by them.

Normally, when the causes and reasons of an event are known and understood, it facilitates taking measures to prevent its occurrence. The mechanisms involved in the onset of chronic postoperative pain are not known in detail; however, with risk factors identification, strategies can be developed to 
reduce its occurrence. Postoperative pain is a risk factor for chronic pain after herniorrhaphy ${ }^{17}$, mastectomy ${ }^{18}$, total hip arthroplasty ${ }^{19}$, and cesarean section ${ }^{12,20}$.

Kainu et al. ${ }^{20}$ used a questionnaire to evaluate 600 patients undergoing vaginal delivery and cesarean section. A correlation between persistent postoperative pain and type of delivery was found one year after the procedure. They reported increased incidence of pain in patients who had undergone cesarean section (18\%), patients who reported pain prior to surgery, and higher level of postoperative pain in patients with chronic disease ${ }^{20}$.

Patients who reported higher scores of postoperative pain in interviews 1 and 2 were more likely to develop chronic pain $(p<0.05)$. These data confirm the findings in literature.

The use of liposoluble opioids via subarachnoid space route in obstetrics has been commonly used because of its synergistic effect with local anesthetics, which provides immediate pain relief and improved quality of anesthesia, as well as prolonged postoperative analgesia and reduced amount of local anesthetic used, which leads to greater safety of the mother-fetus binomial ${ }^{21}$.

Sufentanil is a lipophilic opioid with very rapid onset of action (5 to 10 minutes) and a short half-life (2 to 4 hours) when used in spinal anesthesia. It improves the quality of the blockade and decreases the minimum dose of local anesthetic required ${ }^{22,23}$. We decided to administer sufentanil in groups G1 and G2 for this purpose. Fentanyl (100 ug) used as rescue treatment for patients with intraoperative pain was only necessary in two patients in G1, which proved the benefits of drug combination. However, there were no significant differences between groups 1,2 , and 3 regarding postoperative analgesia (Table II). When group 1 was compared with group 4 (15 mg + 100 ug morphine), a significant difference was seen among them in the control of acute postoperative pain (Table II). Sufentanil was an important intraoperative adjuvant because it allowed the use of spinal anesthesia for cesarean section with small doses of local anesthetic (8 and $10 \mathrm{mg}$ of bupivacaine). Culebras et al. ${ }^{24}$ found that low doses of sufentanil did not potentiate the effect of intrathecal morphine used for postoperative analgesia after colorectal surgery 24 .

In this work, patients undergoing anesthesia with low doses of local anesthetics (G1 and G2) had higher percentages of chronic pain (20\% and $13 \%$ ) compared with the groups that used higher doses of local anesthetics. Reducing the dose of local anesthetic has a limit that, if not respected, may increase the incidence of chronic pain (Table VI). The combination of sufentanil in these two groups did not prevent the onset of chronic pain.

Comparing the two groups receiving the same dose of local anesthetic and morphine (G3 and G5), but with different administration of NSAIDs, we found that the incidence of chronic pain was $7.1 \%$ in the group receiving anti-inflammatory medication and $20.3 \%$ in the group receiving no anti-inflammatory medication.

We conclude that spinal anesthesia for cesarean section with doses of hyperbaric bupivacaine $0.5 \%$ exceeding $10 \mathrm{mg}$, combined with $100 \mu \mathrm{g}$ of morphine and the use of NSAID during the intraoperative and immediate postoperative periods reduces the incidence of chronic pain after three months of the procedure. We also found a correlation between higher pain scores in the immediate postoperative period and a higher incidence of chronic pain. 


\section{REFERENCES}

1. Macrae WA - Chronic pain after surgery. Br J Anaesth, 2001;87:8898.

2. International Association for the Study of Pain - Classification of chronic pain. Descriptions of chronic pain syndromes and definitions of pain terms. Prepared by the International Association for the Study of Pain, Subcommittee on Taxonomy. Pain Suppl, 1986;3:S1-S226.

3. Perkins $\mathrm{FM}$, Kehlet $\mathrm{H}-$ Chronic pain as an outcome of surgery. Anesthesiology, 2000;93:1123-1133.

4. Portal da Saúde 2010. Disponível em: [http://portal.saude.gov.br/portal/saude/visualizar texto.cfm?idtxt=21379] (Acesso em 01/10/2011).

5. Lavand'homme P - Post cesarean analgesia: effective strategies and association with chronic pain. Curr Opin Anaesthesiol, 2006;19:244248.

6. Power I-Recent advances in postoperative pain therapy. $\mathrm{Br} \mathrm{J} \mathrm{An}$ aesth, 2005;95:43-51.

7. Kehlet $\mathrm{H}$, Jensen $\mathrm{TS}$, Woolf $\mathrm{C}-$ Persistent postsurgical pain: risk factors and prevention. Lancet, 2006;367:1618-1625.

8. Pogatzki-Zahn EM, Zahn PK - From preemptive to preventive analgesia. Curr Opin Anaesthesiol, 2006;19:551-555. 
9. Torres MLA, Carlos RV - Condutas analgésicas em cirurgia obstétrica, dor pós-operatória. Sociedade Brasileira de Anestesiologia, Rio de Janeiro, 2004, pp. 289-307.

10. True Random Number Service. Disponível em: [http://www.random. org] (Acesso em 01/01/2009).

11. Neter J, Kutner MH, Nachtsheim CJ et al. - Applied linear statistical models. 4⿳亠丷a . ed. Illinois: Richard D. Irwing, 1996, 1408p.

12. Nikolajsen L, Sorensen HC, Jensen TS et al. - Chronic pain following caesarean section. Acta Anaesthesiol Scand, 2004;48:111-116.

13. Luijendijk RW, Jeekel J, Storm RK - The low transverse Pfannenstiel incision and the prevalence of incisional hernia and nerve entrapment. Ann Surg, 1997;225:365-369.

14. Rafique Z, Shibli KU, Russell IF et al. - A randomized controlled trial of the closure or non closure of peritoneum at caesarean section; effect on postoperative pain. Br Obstet Gynaecol, 2002;109:694-698.

15. Eisenach JC, Pan PH, Smiley R et al. - Severity of acute pain after childbirth, but not type of delivery, predicts persistent pain and postpartum depression. Pain, 2008;140(1):87-94.

16. Sng BL, Sia AHT, Quek K et al. - Incidence and risk factor for chronic pain after caesarean section under spinal anaesthesia. Anaesth Intensive Care, 2009;37:748-752.

17. Aasvang $\mathrm{E}$, Kehlet $\mathrm{H}-$ Chronic postoperative pain: the case of inguinal herniorrhaphy. B J Anaesth, 2005;95:69-76.

18. Poleshuck EL, Katz J, Andrus $\mathrm{CH}$ et al. - Risk factors for chronic pain following breast cancer surgery: a prospective study. Pain, 2006;7:626-634.

19. Nikolajsen L, Brandsborg B, Lucht $U$ et al. - Chronic pain following total hip arthroplasty: a nationwide questionnaire study. Acta Anaesthesiol Scand, 2006;50:495-500.

20. Kainu JP, Sarvela J, Tiippana E et al. - Persistent pain after caesarean section and vaginal birth: a cohort study. Int J Obstet Anesth, 2010;19(1):4-9.

21. Castro LFL, Serafim MM, Côrtes CAF et al. - Avaliação do estado ácido-básico materno com o uso de sufentanil por via subaracnóidea em diferentes doses para cesarianas e suas repercussões sobre os recém-nascidos. Rev Bras Anestesiol, 2003;53(1):17-24.

22. Wang LZ, Zhang YF, Tang BL et al. - Effects of intrathecal and i.v. small-dose sufentanil on the median effective dose of intrathecal bupivacaine for Caesarean section. Br J Anaesth, 2007;98:792-796.

23. Parpaglioni R, Baldassini B, Barbati $G$ et al. - Adding sufentanil to levobupivacaine or ropivacaine intrathecal anaesthesia affects the minimum local anaesthetic dose required. Acta Anaesthesiol Scand, 2009; 53:1214-1220.

24. Culebras X, Savoldelli GL, Gessel EV et al. - Low-dose sufentanil does not potentiate intrathecal morphine for perioperative analgesia after major colorectal surgery. Can J Anesth, 2007;54(10):811-817. 